\title{
DIÁLOGOS POSSÍVEIS: articulação de saberes locais com o ensino de Botânica
}

\author{
DIÁLOGOS POSIBLES: articulación del conocimiento local con la enseñanza \\ de la Botánica
}

\section{ACHIEVABLE DIALOGUES: local knowledge interaction with botanical education}

\author{
Leandro Nogueira Batista ${ }^{1}$ \\ https://orcid.org/0000-0002-6069-0352 \\ José Vicente de Souza Aguiar ${ }^{2}$ \\ http://orcid.org/0000-0001-7754-1620
}

\begin{abstract}
Resumo
Este trabalho se configura a partir do resultado da pesquisa no âmbito do mestrado acadêmico do Programa de Pós-graduação em Educação e Ensino de Ciências na Amazônia, e tem por objetivo a compreensão do diálogo entre o saber local sobre o cultivo da mandioca com o processo de ensinoaprendizagem de Botânica no Ensino Médio a partir da articulação entre diferentes saberes. Visa, ainda, ressaltar a necessidade de evidenciar um saber com base nas experiências de vida que são constituídas de significados para os sujeitos que as experienciam, embora tais sujeitos sejam, às vezes, ofuscados e considerados como acríticos, ingênuos e não-ocidentalizados, dentre outras denominações, em detrimento de outro saber considerado científico. Essa compreensão se faz necessária para questionar a ideia de que ambos conhecimentos (local e científico) são incomensuráveis. Quando articulados aos conhecimentos escolares podem fazer sentido, além de poderem ser aplicados na tomada de decisões acerca de problemas reais do cotidiano. Os resultados foram analisados de maneira interpretativa numa perspectiva fenomenológica, apontam a contribuição para o processo de ensino-aprendizagem em Botânica a partir do estabelecimento de um diálogo entre o saber local sobre o cultivo da mandioca, sobretudo no que diz respeito à percepção dos estudantes no que tange à relação com o ensino e sua cotidianidade.
\end{abstract}

Palavras-chave: Saber. Cultivo da mandioca. Ensino Médio. Saberes locais.

\section{Resumen}

Este trabajo se configura a partir del resultado de una investigación dentro de la maestría académica del Programa de Postgrado en Educación y Enseñanza de las Ciencias en la Amazonía, y

\footnotetext{
${ }^{1}$ Mestre em Educação e Ensino de Ciências - Universidade do Estado do Amazonas/Escola Normal Superior. Fundamentos da Educação e Ensino de Ciências - GEPFEEC. leandrobatistta@outlook.com.br

2 Doutor em Educação - Universidade do Estado do Amazonas/Escola Normal Superior. Fundamentos da Educação e Ensino de Ciências - GEPFEEC.Vicenteaguiar1401@gmail.com
}

\section{Como referenciar este artigo:}

BATISTA, L.N.; AGUIAR, J.V.S. Diálogos possíveis: articulação de saberes locais com o ensino de Botânica. Revista Pedagógica, v.23, p. 1-24, 2021. 
tiene como objetivo comprender el diálogo entre los saberes locales sobre el cultivo de la yuca con el proceso de enseñanza-aprendizaje de la Botánica en la Educación Secundaria a partir de la articulación entre diferentes saberes. También pretende destacar la necesidad de resaltar un conocimiento basado en las experiencias vitales que se constituyen en significados para los sujetos que las experimentan, aunque a veces dichos sujetos son eclipsados y considerados acríticos, ingenuos y no occidentalizados, entre otras denominaciones, en detrimento de otros conocimientos considerados científicos. Esta comprensión es necesaria para cuestionar la idea de que ambos conocimientos (el local y el científico) son inconmensurables. Cuando se articulan al conocimiento escolar pueden tener sentido, además de poder aplicarse en la toma de decisiones sobre problemas reales de la vida cotidiana. Los resultados fueron analizados interpretativamente desde una perspectiva fenomenológica, señalan la contribución al proceso de enseñanzaaprendizaje de la Botánica a partir del establecimiento de un diálogo entre los conocimientos locales sobre el cultivo de la yuca, especialmente en lo que respecta a la percepción de los estudiantes en cuanto a la relación con la enseñanza y su vida cotidiana.

Palabras clave: Conocimiento. Cultivo de la yuca. Escuela secundaria. Conocimiento local.

\begin{abstract}
This article constitutes, from the research results, as part of the academic master's degree in the Post-graduation Program of Education and Science Teaching in the Amazon, and it aims toward the dialogue comprehension between the local knowledge over cassava growing and the teachinglearning process of Botany in High School, as of the interaction among different knowledges. Furthermore, it aims to emphasize the necessity of showing a knowledge based on life experiences that are constituted of meanings to the subjects who experience them, though these subjects, sometimes, are overshadowed and recognized as uncritical, ingenuous, and non-westernized, among other denominations, to the detriment of another knowledge deemed scientific. This comprehension is necessary to question the idea that both knowledges (local and scientific) are immeasurable and when they are articulated to the scholar knowledge, they might make sense besides being able to be implemented in decision making about real problems of everyday life. The results were analyzed in an interpretative approach within a phenomenological perspective, which pointed out the teaching-learning process in Botany as of the establishment of a dialogue between the local knowledge over cassava growing, regarding, above all, the students' perception in relation to education and their daily life.
\end{abstract}

Keywords: Knowledge. Cassava growing. High school. Local knowledge.

\title{
INTRODUÇÃO
}

O ser humano, ao perceber o mundo, constrói conhecimentos a partir da dinâmica com a natureza. Nessa perspectiva, entende-se que muitos conhecimentos, hoje considerados científicos, tiveram e têm sua gênese a partir das percepções e experiências empíricas no mundo vivido onde sua existência se realiza. 
Revista do Programa de Pós-Graduação em Educação da Unochapecó

ISSN 1984-1566 (on-line) ISSN 1415-8175 (impressa)

Esses conhecimentos não se configuram como senso comum, mas em um saber construído pela dinâmica do ser humano com o lugar onde vive e estabelece estritas relações com ele, a ponto de pensar e "ver" o mundo por uma racionalidade diferente da científica.

Nesse sentido, entende-se que os estudantes possuem saberes oriundos de suas experiências de vida, sendo estes, constituídos de significado que lhes permitem pensar e ver o mundo de maneira diferente daquela que ressalta a racionalidade científica. Boaventura Santos (1988), discute que o conhecimento da Ciência fecha as portas a muitos outros conhecimentos sobre o mundo e de acordo com essa característica, tal conhecimento científico moderno exclui as outras formas de saber.

Tomando esse questionamento como base, entende-se que o Ensino de ciências necessita ser articulado às experiências de vida dos estudantes, levando em conta a realidade local e as particularidades desse meio em detrimento do processo de ensinoaprendizagem. Em relação ao ensino de Botânica, chama-se a atenção para a forma em que é ensinada requer do estudante o recurso da memória para decorar a Taxonomia (classificação e organização das plantas) e habilidade para lidar com muitos nomes da nomenclatura botânica ${ }^{3}$. Essa exigência tem sua importância, mas ela se circunscreve a uma necessidade fundamental que deve possuir o especialista em Botânica, enquanto os estudante da Educação Básica são iniciantes na linguagem científica.

É preciso destacar que os nomes das diversas estruturas a serem aprendidas são, muitas vezes, ensinados de maneira predominantemente teórica, comprometendo o processo de ensino-aprendizagem. Dutra e Güllich (2014, p. 493) consideram a botânica como "[...] uma das áreas mais prejudicadas no que se refere ao ensino. Seja pela complexidade de termos, precariedade de materiais e ambientes para se trabalhar, dificuldades de abordagens ou mesmo pela falta de formação dos docentes".

Sabe-se que tais afirmações levantadas pelos autores constitui um desafio ao ensino desta área, principalmente no Ensino Médio. Assim, considera-se destacar o universo temático do estudante como ponto de partida para o processo de ensino-aprendizagem pois, na escola, frequentemente, os saberes das experiências estão subjacentes aos

\footnotetext{
${ }^{3}$ Que nomeia as plantas com base em regras específicas.
} 
procedimentos pedagógicos utilizados com foco mais num processo mnemônico ou que não os valorize mais efetivamente.

Partindo da compreensão de saber local, entende-se que dar voz aos saberes tidos como não ocidentalizados, que são rotulados como acríticos, ingênuos ou senso comum como lembra Geertz (2014), podem contribuir com o processo de ensino-aprendizagem em Botânica no Ensino médio.

Assim, ao pensarmos nos modos de vida dos povos da Amazônia, que às vezes são considerados pejorativamente em relação aos que vivem nos centros urbanos, dedicados à agricultura como meio de produção da existência, não se pode entendê-los como pessoas desprovidas de significação, mas, pelo contrário, como possuidoras de conhecimentos construídos a partir de suas experiências e que são capazes de construírem modos específicos de ser, de pensar e de viver.

Estabelecer um diálogo entre esses saberes (o local e o científico sobre a natureza vegetal) pode ser uma forma de contribuir para o processo de ensino-aprendizagem dos estudantes no que diz respeito à aquisição das competências indicadas pela BNCC para área de Ciências da natureza e suas tecnologias onde se encontra inserida a área de Botânica pertencente à Biologia, tais como indicada pela competência específica 3 do referido documento:

Investigar situações-problema e avaliar aplicações do conhecimento científico e tecnológico e suas implicações no mundo, utilizando procedimentos e linguagens próprios das Ciências da Natureza, para propor soluções que considerem demandas locais, regionais e/ou globais (BRASIL, 2018, p. 558).

Essas competências permitem aplicabilidade no cotidiano, ou seja, o saber-fazer, e não apenas "aprender" por que é uma exigência escolar, mas para dar sentido ao aprendizado, já que "[...] toda consciência é consciência de algo" como diz Merleau-Ponty (2018, p. 26). Ao mesmo tempo, aquilo que não tem sentido se esvai na temporalidade - o que norteia nossas vidas está intimamente relacionado ao modo como percebemos o 
Revista do Programa de Pós-Graduação em Educação da Unochapecó

ISSN 1984-1566 (on-line) ISSN 1415-8175 (impressa)

mundo - o desinteressado ${ }^{4}$ foge à minha consciência, mas o significado permanece como essência.

Esse trabalho se configura como resultado da pesquisa de mestrado no âmbito do Programa de Pós-graduação em Educação e Ensino de Ciências na Amazônia da Universidade do Estado do Amazonas, cujo objetivo visou compreender possíveis articulações de saberes locais de agricultores sobre o cultivo da mandioca com o processo de ensino-aprendizagem de Ensino de Botânica no $3^{\circ}$ ano do Ensino Médio.

A seguir trataremos da ciência como saber hegemônico constituida por paradigmas, por seus métodos e sua articulação com o ensino escolar. Ao mesmo tempo, se buscou pensar um "Saber Outro": ver e pensar o mundo em diferentes racionalidades. O caminho da pesquisa deu-se pela perspectiva fenomenológica, que se procurou conhecer o ser humano no campo de sua facticidade, de suas experiências no mundo. Por último, foi estabelecida a articulação entre os saberes locais ao Ensino de Botânica, de modo a indicar a existência da possiblidade de diálogos entre saberes.

\section{CIÊNCIA COMO SABER HEGEMÔNICO}

O físico e filósofo Thomas Kuhn, em sua obra A estrutura das revoluções científicas (1998) discute o conceito de paradigma, sendo este um modelo, um padrão aceito, ou seja, aquele que deve ser seguido, reproduzido. Diz-se dominante, porque impera diante de outros modelos não estabelecidos, ou fora da concepção ideal a ser seguida, o não globalizado (na ideia de universal). Analogamente, pode-se pensar na ideia da Ciência como um paradigma dominante na medida em que deixa de considerar outros conhecimentos vistos como não científicos.

A Ciência nessa perspectiva carrega o status de saber hegemônico ${ }^{5}$, aquele tido como universal, o verdadeiro, por ter passado por vários critérios estabelecidos pela comunidade científica e reconhecido pela maioria. Para Thomas Kuhn, esse modelo

\footnotetext{
${ }^{4}$ Utilizamos o termo "desinteressado" baseado naquele utilizado por Claude Lévi-Strauss na obra Mito e Significado (1978) em que, por ocasião de observação da vida do nativo, ele usa o termo pensamento desinteressado para ressaltar a diferença no modo de perceber e pensar o mundo pelos povos primitivos. 5 Termo utilizado por Leite \& Leite em Saber local e saber formal: divergências e assimetrias. In: Ciências \& cognição, 2012, . 17 (2): 135-154 http://www.cienciasecognicao.org. Acesso em 21 maio 2018.
} 
Revista do Programa de Pós-Graduação em Educação da Unochapecó

ISSN 1984-1566 (on-line) ISSN 1415-8175 (impressa)

engloba um conjunto de valores, teorias e métodos que irão influenciar a comunidade científica, "o sucesso de um paradigma [...] é, em grande parte, uma promessa de sucesso que pode ser descoberta em exemplos selecionados e ainda incompletos" (KUHN, 1998, p. 44).

Entretanto, neste mundo multicultural, existem outras maneiras de ver, de pensar, de sentir e de agir, as quais revelam que a Ciência com todo seu status e hegemonia, na verdade, divide espaço com outras racionalidades para além daquilo tido como científico. Ressalta-se que não se pretende dar descrédito aos avanços outrora alcançados pela Ciência.

Boaventura Santos (1988) chama a Ciência moderna de paradigma dominante, apontando que este modelo de racionalidade se constituiu a partir da Revolução Científica do século XVI e se desenvolveu nos séculos seguintes no domínio das ciências naturais e a partir do século XIX passou a ser visto como um modelo global de racionalidade científica. Ele considera que esse paradigma dominante, sendo um modelo global, também se constitui como “[...] um modelo totalitário, na medida em que nega o caráter racional a todas as formas de conhecimento que se não pautarem pelos seus princípios epistemológicos e pelas suas regras metodológicas (SANTOS, 1988, p. 48).

O autor deixa evidente a exclusão de outras maneiras sobre as formas de pensar os fenômenos senão aqueles estabelecidos pelo que chama de Ciência Moderna, pois não teriam um "rigor" científico necessário. Mas o que seria esse rigor científico? Em Kuhn (1998), um conjunto de procedimentos (paradigmas e método científico) aceito pela maioria dos cientistas, considerando que "a ciência é o processo de produção da verdade, é o trabalho dos cientistas - os trabalhadores da prova - no processo de reorganização da experiência em um esquema racional" (LOPES, 1996, p. 253).

A Ciência desvaloriza o fato de que muitos conhecimentos hoje considerados científicos tiveram e têm sua gênese a partir das percepções e experiências empíricas, não está se falando de senso comum, mas de um saber construído pela dinâmica do ser humano com o lugar onde vive e que estabelece estritas relações com ele, a ponto de pensar e "ver" o mundo por vias diferentes das científicas.

Busca-se dialogar com o antropólogo estruturalista Claude Lévi-Strauss que traz contribuições para essa abordagem. Na obra Mito e Significado (1978), Lévi-Strauss revela 
crer que há certas coisas que perdemos e que devíamos fazer um esforço de conquistá-las novamente. Isso faz questionar sobre uma possível relação do saber local com o modo de pensar pela ciência na medida em que se pretende dialogar entre saberes.

Nesse sentido, Lévi-Strauss destaca que, na sua visão, não se vê seguro de que possa reconquistar tais coisas como se nunca as tivéssemos perdido no tipo de mundo em que vivemos e com o tipo de pensamento científico a que estamos sujeitos. A essa altura o autor refere-se ao distanciamento da Ciência e o mito, mas afirma que, na verdade, a Ciência "não está se afastando destas matérias perdidas, e que, pelo contrário, tenta cada vez mais reintegrá-las no campo da explicação científica” (LÉVI-STRAUSS, 1978, p. 10).

Para ele, foi nos séculos XVII e XVIII que a Ciência da compreensão rompeu com o que ele chama de velhas gerações de pensamento, referindo-se a Bacon, Descartes e Newton. A partir de então, para a ciência afirmar seu estatuto, deveria voltar às costas ao mundo dos sentidos, ou seja, o mundo que vemos, cheiramos, saboreamos e percebemos (LÉVI-STRAUSS, 1978).

É nesse sentido que Merleau-Ponty considera a experiência como abertura ao nosso mundo de fato e a partir do momento em que ela "[...] é reconhecida como o começo do conhecimento, não há mais nenhum meio de distinguir um plano de verdades a priori e um plano das verdades de fato, aquilo que o mundo deve ser e aquilo que efetivamente ele é" (MERLEAU-PONTY, 2018, p. 298).

É sob essa perspectiva apontada por Merleau-Ponty que se pauta a necessidade de abordagem dos saberes locais como uma via de aproximação ao Ensino de Ciências, em particular à Botânica, área de conhecimento da Biologia. Busca-se refletir sobre as diferentes formas de ver e pensar o mundo.

\section{UM “SABER OUTRO” : VER E PENSAR O MUNDO EM DIFERENTES RACIONALIDADES}

Lévi-Strauss (1978) contribui com essa reflexão quando ressalta que a Ciência tem seus méritos pelo "divórcio" com outras formas de racionalidade, ou seja, o distanciamento do pensamento científico, que instituiu o que ele chamou de lógica do concreto. Isto foi, segundo ele, necessário para o desenvolvimento do pensamento científico. 
Revista do Programa de Pós-Graduação em Educação da Unochapecó

ISSN 1984-1566 (on-line) ISSN 1415-8175 (impressa)

O autor chama atenção para não pensarmos que ele defende a eliminação dessa diferença, “[...] na realidade as diferenças são extremamente fecundas. O progresso só se verificou a partir das diferenças" (LÉVI-STRAUSS, 1978, p. 22). Nesse sentido, são evidentes diferentes formas de pensar e ver o mundo, onde uma segue linha estritamente lógica, objetiva e racional do ponto de vista científico; já a outra segue caminho oposto, considerando uma visão sobre o mundo, a experiência de vida no mundo, a facticidade, que só se realiza num retorno às coisas mesmas (MERLEAU-PONTY, 2018).

A forma como vemos o mundo e o experienciamos reflete nas situações de nossas vidas e ao adentrar esse "mundo" diferente, corremos o risco de colocá-lo a mercê de nossos juízos, essa é a ideia refletida na Ciência. Desse modo, a convivência com as diferenças é inevitável. Apesar disso, se seguimos os padrões relacionados à racionalidade científica, temos uma visão de mundo, enquanto um agricultor, por exemplo, que realiza suas práticas cotidianas de cultivo agrícola, o vê de forma diferente, ao mesmo tempo em que nos nos encontramos no mesmo mundo e na mesma temporalidade.

Logo, é baseado no sentido que damos ao vivido, por meio das nossas percepções e subjetividades que estamos postos ao contato com os diferentes saberes, pois o que muda é a forma de ver o mundo, de percebê-lo. Essas "coisas" que agora ficam mais claras e que já se havia mencionado em Lévi-Strauss (1978) se referem “a este mundo anterior ao conhecimento do qual o conhecimento sempre fala" (MERLEAU-PONTY, 2018, p. 4).

Cada ser possui saberes voltados à sua realidade, que são construídos na dinâmica das relações sociais, afetivas, enfim, com o mundo vivido. Esse saber é chamado local não somente em detrimento ao lugar, mas com base em suas caracterizações vernaculares (GEERTZ, 2014). Nesse sentido, cada saber é altamente necessário ao modo de vida de cada um e é nisso que Lévi-Strauss faz refletir, “[...] não podemos exigir que toda a gente esteja interessada precisamente nas mesmas coisas; daí que cada um de nós utilize uma certa porção do seu poder mental para satisfazer as necessidades ou alcançar as coisas que o interessam" (LÉVI-STRAUSS, 1978, p. 20).

Entende-se que os saberes mediados por povos de um determinado local ou comunidade, acabam sendo suprimidos pelo saber dito científico assim como o das comunidades tradicionais, pelo simples fato de nortearem suas vidas por uma racionalidade diferente. 
Essa discussão ajuda a compreender uma pluralidade de saberes e que se deve dar voz a eles, mesmo estando "à margem" do saber considerado válido. Ressalta-se, então, opção por esse "saber outro" por entender que podem contribuir para o ensinoaprendizagem no Ensino de Ciências. Para isso, busca-se fundamentos em Merleau-Ponty ao afirmar que a Ciência sempre será expressão segunda da experiência do mundo, uma vez que todo o universo da ciência se constrói sobre o mundo vivido (MERLEAU-PONTY, 2018).

Segundo Santos (1988), a ciência se torna ignorante na medida em que consagra o homem como ser epistêmico, mas o expulsa enquanto sujeito empírico. É por conta disso que Lévi-Strauss (2008, p. 17) salienta que, “[...] essa ânsia de conhecimento objetivo constitui um dos aspectos mais negligenciados do pensamento daqueles que chamamos 'primitivos"'.

Considerando o ser humano como um ser inacabado, incompleto mediante o mundo-vida, a aquisição de novos saberes o modifica, sua consciência é tocada, o que permite aprimorar ou modificar também suas percepções. Foucault ressalta que "há saberes que são independentes das ciências (que não são nem seu esboço histórico, nem o avesso vivido); mas não há saber sem uma prática discursiva definida, e toda prática discursiva pode definir-se pelo saber que ela forma" (FOUCAULT, 2008, p. 205). Então, nessa perspectiva fica mais próxima à possibilidade de estabelecer um diálogo entre os saberes.

\section{CAMINHO METODOLÓGICO}

A presente pesquisa apresenta natureza qualitativa, cuja obtenção de dados se deu no ambiente onde os próprios sujeitos vivenciam o fenômeno que está sendo investigado.

Em direção a uma dimensão cognitiva do ser (a percepção), optou-se pelo enfoque fenomenológico. Buscou-se suporte na Fenomenologia da percepção de Maurice MerleauPonty (2018), pois “[...] o pesquisador fenomenológico busca sempre interpretar seus dados a partir de um referencial filosófico que fundamenta a sua reflexão, o seu pensar" (FINI, 1994, p. 31). 
Adotou-se a pesquisa de campo visando observar o fenômeno da maneira como ocorre na realidade, isso através do contato próximo aos agentes sociais. Segundo Becker (1993, p. 91), “o pesquisador de campo, devido ao fato de que tem um contato contínuo com aqueles que estuda, pode coletar dados deles através de variados procedimentos, em diversos ambientes e em diferentes estados de espírito".

Denominou-se os sujeitos desta investigação de agentes sociais conforme Bourdieu (2008). Participaram dois agricultores de uma comunidade do interior da cidade de Parintins do Estado do Amazonas, cujos nomes aqui descritos são fictícios como forma de manter sua integridade, estes foram acompanhandos em sua cotidianidade para desvelar saberes sobre o cultivo e produção da mandioca por eles realizado. Na articulação dos saberes, participaram 21 alunos de duas turmas do $3^{\circ}$ ano do ensino médio vespertino de uma escola pública da cidade de Parintins no Amazonas.

Como técnica de coleta de dados utilizou-se a observação livre e a participante, pela qual o pesquisador obtém dados, "[...] através de sua participação na vida cotidiana do grupo ou organização que estuda. Ele observa as pessoas que está estudando para ver as situações com que se deparam normalmente e como se comportam diante delas" (BECKER, 1993, p. 47), cuja coleta de dados ocorreu entre março a outubro de 2019.

Foram realizadas observações em sala de aula da educação básica na disciplina Biologia, com o intuito de conhecer como acontece a articulação entre saberes advindos da experiência de vida dos estudantes relacionados com os conhecimentos escolares.

Para articulação, visando o diálogo entre os saberes, utilizou-se uma roda de conversa e uma oficina a partir de uma sequência didática. Na análise dos dados, utilizouse três momentos ou aspectos necessários na perspectiva fenomenológica: a epoché, a redução e a interpretação fenomenológica. A epoché significa a suspensão do fenômeno, “dar um passo atrás" e parar com as formas comuns de olhar as coisas. A redução é a descrição do visto, ambas compõem o chamado princípio hermenêutico, quer dizer interpretação, a não hierarquização prévia dos fenômenos (MARTIN; BICUDO, 1983; BICUDO, 1994).

Este trabalho, como resultado de pesquisa realizada no âmbito do mestrado acadêmico em Educação e Ensino de Ciências teve seu parecer aprovado pelo Comitê de Ética em pesquisa que trata com seres humanos identificado com CAAE 
Revista do Programa de Pós-Graduação em Educação da Unochapecó ISSN 1984-1566 (on-line) ISSN 1415-8175 (impressa)

08603019.3.0000.5016 e número do parecer 3.212.155, sendo que foram utilizados todos os procedimentos para resguardar a identidade dos agentes sociais envolvidos. No caso dos estudantes, um termo de consentimento foi assinado autorizando o uso de suas imagens.

Os resultados tratam das observações das atividades realizadas no espaço escolar, de modo a identificar os conhecimentos dos alunos sobre Botânica; em seguida foram desenvolvidas atividades articuladas entre o Ensino de Botânica às experiencias dos alunos, por último ocorreram as oficinas "Diálogo entre Saberes": uma perspectiva fenomenológica como vista a articular o saber escolar aos conhecimentos tradicionais.

\section{RESULTADOS E DISCUSSÕES}

Durante as aulas observadas, os estudantes elaboraram seminários para explicar os conteúdos da disciplina Biologia. Nesse momento, ficava-se atento para verificar se relacionavam o conteúdo exposto a algo de seu cotidiano, de modo a expressar saberes de suas experiências.

Em uma apresentação de seminários em grupo que falava sobre Nematódeos, especificamente sobre o bicho geográfico, causado pelas larvas dos vermes Ancylostoma brasilienze e Ancylostoma caninum, um estudante relatou que quando havia sido acometido, sua avó o ensinou um método para eliminação do verme, que para isso teria que pingar gotas de parafina de vela em cima do local afetado. Segundo o estudante, o procedimento era doloroso, mas, no seu ponto de vista, gerava bom resultado.

Esta experiência foi compartilhada em sala de aula para os demais colegas, alguns disseram conhecer o procedimento. É válido ressaltar que a professora não desprezava esses saberes prévios. Este relato evidencia um tipo de saber não científico, baseado em suas experiências de vida, que demonstra que é passível de relacionar aos conteúdos escolares tudo aquilo que faz sentido para ele.

Essas experiências do fenômeno se revelaram através da observação nesse contato próximo do espaço vivido, a partir da interação com os agentes na escola. No geral, as relações com a questão do cultivo e manifestação de saberes não foi evidente. 


\subsection{Articulação de saberes locais ao Ensino de Botânica}

Inicialmente realizou-se uma roda de conversa cujo objetivo foi conhecer sobre a vivência dos estudantes em relação à temática de pesquisa, além de ampliar os significados de suas concepções e possíveis saberes sobre Botânica.

Esta se deu a partir das seguintes questões de direcionamento que se pretendia conhecer e compreender: O que significa para você estudar Botânica? Como você vê os saberes locais? Você tem contato com as plantas no seu cotidiano? Se sim, como é? Você ou alguém da sua família realizam atividades de plantio/cultivo? Se sim, quais? Você ou sua família utilizam as plantas para alguma finalidade?

A "roda de conversa" foi realizada no dia 02 de outubro de 2019. Em um primeiro momento, pediu-se aos estudantes que falassem sobre o significado de estudar Botânica. Para eles, estudar Botânica aponta para conhecer as estruturas, a classificação e as funções de uma planta, enfim, os seus aspectos biológicos. O relato expressa o que eles responderam "Pra conhecer as plantas, as estruturas, a parte científica delas, pra que servem" (ESTUDANTES, out. de 2019).

Quanto aos saberes locais, suas concepções apontam para uma forma de saber em relação à utilização das plantas, pois eles comentavam sempre fazendo referência a seus pais ou avós, o que permitiu perceber que quando respondiam se alguém de sua família utilizava as plantas para alguma finalidade, era no sentido da utilização para fins medicinais “A minha avó usa pra fazer chá, pra dor de estômago, essas coisas" ou ainda, somente para paisagismo "Lá em casa a mamãe só tem planta pra enfeitar" (ESTUDANTES, outubro de 2019). Os estudantes revelaram pouco contato com as plantas de forma direta.

Realizou-se uma dinâmica denominada "experiência dos sentidos" com a seguinte questão em plano de fundo: Como o estudante percebe a Botânica e os saberes locais em seu cotidiano? Essa atividade ocorreu a partir da organização em grupos de quatro integrantes.

Foi apresentada a eles a "caixa surpresa" com a explicação de que dentro dela havia vários objetos e que cada grupo deveria trabalhar junto para descobri-los. Cada grupo escolhia um membro por rodada e seus olhos eram vendados, outro integrante retirava da 
caixa um objeto e, sem dar dicas, o integrante com os olhos vendados deveria usar os sentidos para identificá-lo (Figura 1).

A caixa continha objetos relacionados à Botânica e aos saberes locais, selecionados a partir da cotidianidade dos estudantes, como por exemplo, papel, farinha, óleos medicinais, chás, folhas, dentre outros. Após quatro rodadas, os estudantes foram levados a pensar e dialogar sobre qual a relação que eles viam daqueles objetos por eles descobertos com a temática trabalhada.

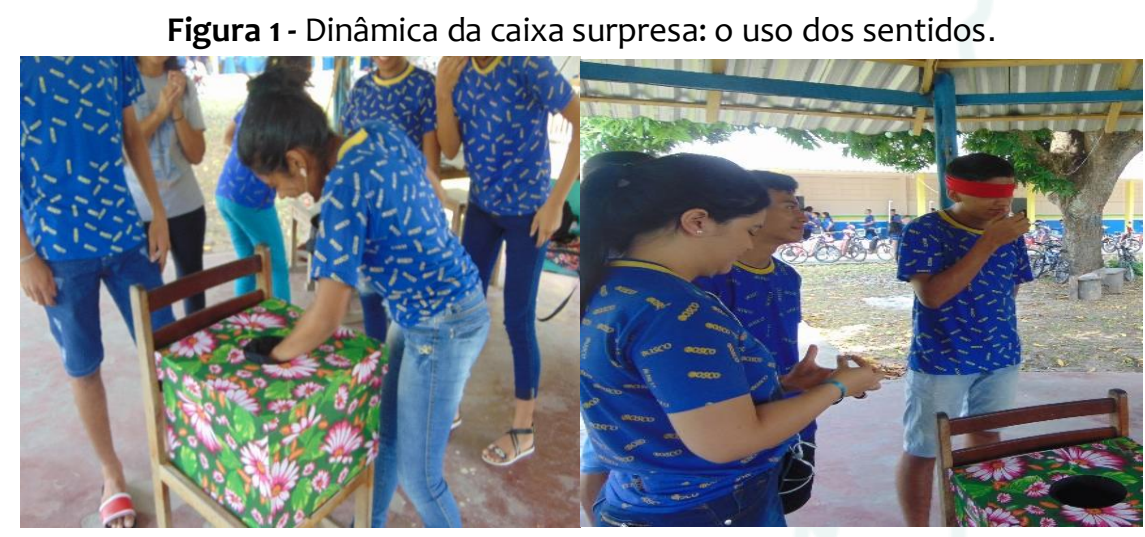

Fonte: Pesquisa de campo, Batista, 2019.

Destacaram a andiroba como um óleo medicinal, extraído da andirobeira, utilizada como remédio medicinal pelas comunidades; a farinha, como um alimento que não pode faltar na mesa conforme destacou a maioria; a tapioca, derivado da mandioca, que serve de alimento. Todos esses produtos são extraídos das plantas e utilizados como recurso pelo ser humano ao longo do tempo.

Explicou-se aos estudantes que esses produtos fazem parte de seu dia a dia e que possuem relação com o ensino de Botânica, que seu estudo não se refere somente a aprender nomes científicos e tantas outras classificações mas, que está presente em seu dia a dia e a partir dos conhecimentos escolares, podem ser articulados aos problemas do seu cotidiano.

\subsubsection{Oficina “Diálogo entre Saberes": uma perspectiva fenomenológica}


Revista do Programa de Pós-Graduação em Educação da Unochapecó

ISSN 1984-1566 (on-line) ISSN 1415-8175 (impressa)

Como forma de valorização dos saberes locais e das experiências de vida realizouse uma oficina intitulada "Diálogo entre Saberes", que ocorreu na semana seguinte após a Roda de conversa, no dia nove de outubro de 2019. Essa oficina foi dividida em quatro momentos descritos a seguir. Vinte e um alunos participaram desta atividadennde foram intercalados momentos realizados no laboratório de Ciências e na área externa da escola e a partir da descrição dos saberes locais da obtenção dos dados com os agentes sociais agricultores, promoveu-se a articulação com o ensino de botânica utilizando o conhecimento sobre o cultivo da mandioca.

No primeiro momento, organizado no Laboratório de Ciências, foi apresentada aos estudantes a espécie botânica "mandioca" como é conhecida popularmente, cujo nome científico Manihot esculenta Crantz. Iniciou-se falando da relação com a cotidianidade dos agricultores e para a realidade local, pois é uma planta presente em seu dia a dia, substancial ao seu modo de existência e, no caso dos estudantes, mesmo que apenas por meio de seus derivados ${ }^{6}$.

Explicou-se que os agentes sociais (referindo-se aos agricultores) conhecem e classificam essas plantas segundo um saber local aprendidos na vivência e proximidade com ela. Apesar de os estudantes conhecerem essa espécie de planta por meio da alimentação e seus derivados, desconheciam sua classificação científica. Quando apresentada essa classificação, expressaram curiosidade e demonstraram dificuldade de pronunciar verbalmente o nome científico mandioca Manihot esculenta.

Os participantes perceberam a familiaridade com os termos populares (mandioca, macaxeira e aipim por exemplo) e inclusive de saberes a ela associados a partir da cotidianidade local quando perguntado: "Que produtos podem ser feitos a partir da mandioca?" eles disseram quase que ao mesmo tempo: “A farinha!”, “o tucupi”, “a tapioca”.

Um estudante perguntou: “E a macaxeira?”, sendo a ocasião aproveitada para explicar que popularmente a mandioca é chamada de "brava" e a macaxeira de "mansa", possuindo então variedades. "Todas pertencem a mesma espécie [...] A diferença entre bravas e mansas se dá apenas pelo teor dos precursores de ácido cianídrico que se

\footnotetext{
${ }^{6}$ Produtos que tem origem a partir do processamento da mandioca como, por exemplo, a farinha.
} 
encontram nas diversas partes do pé, das folhas ao tubérculo" (IPHAN, 2010, p. 57). Em outras regiões, as variedades mansas recebem nomenclaturas locais como mandioca, macaxeira, aipim, dentre outras. No entanto, foi esclarecido que essas são formas de designações locais para descrever e classificar a espécie da planta Manihot esculenta.

No segundo momento, os estudantes foram levados até a área externa da escola onde se encontrava um pequeno plantio de macaxeira ( $M$. esculenta), que fazia parte de um projeto anteriormente desenvolvido na escola e que não estava em andamento. Lá, ao redor de uma espécie da planta macaxeira, foi pedido que eles a observassem e fizessem dez descrições sobre ela (Figura 2), usando a percepção e os sentidos.

Figura 2 - Estudantes observam a planta mandioca para realizar a descrição.

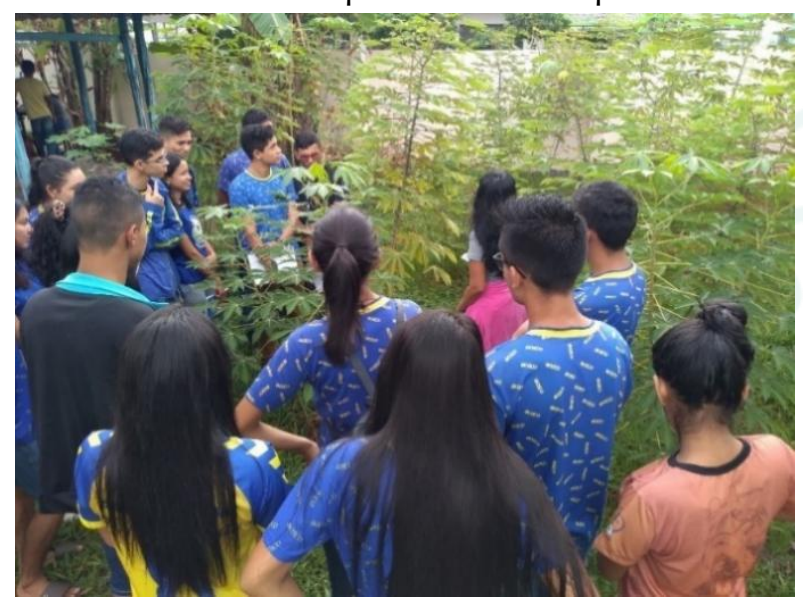

Fonte: Batista, 2019.

Ao redor da planta macaxeira, começaram a realizar sua descrição. Eles olhavam para ela e se perguntavam o que escrever. Os estudantes levaram cerca de quinze minutos para realizar dez descrições sobre aquela variedade de mandioca. Todos estavam como que admirando-a, parados a certa distância, alguns deles se aproximaram um pouco mais, mas nenhum deles sequer a tocou. Pareciam esperar um tipo de comando para tocá-la ou executar outra ação.

Após terminarem a descrição, os estudantes foram questionados sobre as anotações que haviam feito numa folha de papel, o que contribuiu para o tratamento dos dados. Realizou-se a categorização das descrições, apresentada na figura a seguir:

Figura 3 - Categorização das descrições dos estudantes. 


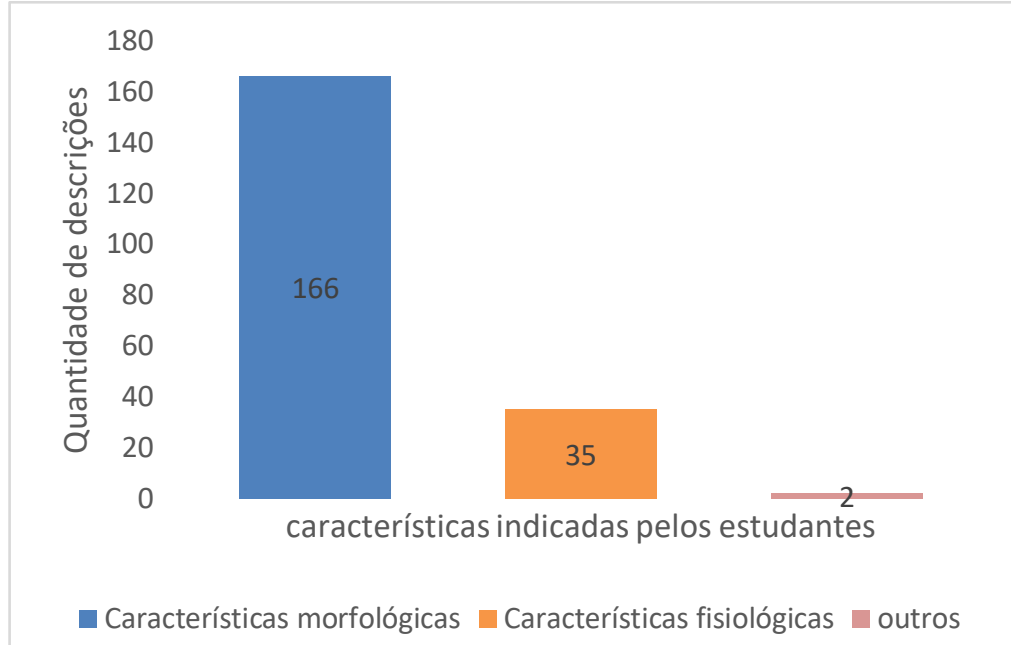

Fonte: Elaborado por Batista; Aguiar, 2020.

Eles disseram "ah professor, foi difícil”, "não sabia o que escrever", "não tem muita coisa pra falar da planta não professor" (ESTUDANTES, out. de 2019). As descrições em sua maioria foram restritas à características morfológicas (166 descrições). Como exemplo, descreve-se: "possui caule, folhas e raízes"; "possui tons verde e marrom"; "possui folhas abertas, tipo estrelas"; "caule fino e marrom"; "tem caule reto e longo, como uma vara" (ESTUDANTES, out. de 2019). Percebeu-se que em alguns casos, fizeram associações para relacionar.

As características fisiológicas vieram em seguida com trinta e cinco (35) descrições. Eles escreveram: "possui mecanismos de defesa contra larvas e mosquitos"; "se desenvolve"; "reprodução sexuada e assexuada”. A categoria outros obteve 2 descrições, a saber: "iguarias" e "parece rústica" (ESTUDANTES, out. de 2019)".

Algumas descrições revelam um saber mais refinado, noutros casos, informações equivocadas, no entanto, vale ressaltar que a pretensão para esse estudo não foi medir a aprendizagem, mas as questões colocadas de maneira equivocada no momento das discussões eram esclarecidas, bem como as dúvidas por eles apresentadas, pois a intenção do estudo era identificar os conhecimentos dos alunos sobre a Botânica na articulação entre os saberes escolares e os do mundo da vida.

Por não terem tocado na planta, quando perguntados, disseram: "ah professor, não sei, acho que sim". Foi dito que a percepção vai além do "ver" com os olhos, que eles 
poderiam ampliar os sentidos, tocando-a poderiam sentir a textura da folha, do caule, por exemplo, e considerar as sensações ao realizar esse procedimento, pois,

[...] a percepção assim empobrecida torna-se uma pura operação de conhecimento, um registro progressivo das qualidades e de seu desenrolar mais costumeiro, e o sujeito que percebe está diante do mundo como o cientista diante de suas experiências (MERLEAU-PONTY, 2018, p. 50).

Foi possível perceber que em alguns momentos eles recorreram à memória para realizar a descrição, ao que já estava em sua cognição, como descrito: “é heliófita”, "possui raiz que é seu principal produto"; "pode chegar a mais de dois metros"; "principal produto é a raiz" (ESTUDANTES, out. de 2019). Os conceitos construídos acerca dela a partir de experiências anteriores permitiu descrevê-la. Mesmo que a planta não estivesse ali, eles conseguiriam fazer a descrição. O exemplo disso é que, não viram a raiz pois estava sob o solo, porém, o conceito de que ela é heliófita, ou seja, depende da luz solar, já estava construído, revelando um saber mediado pela escolarização.

Segundo Merleau-Ponty (2018), antes de alguma contribuição da memória, o que se vê deve presentemente se organizar de maneira a me oferecer um quadro em que seja possível reconhecer minhas experiências anteriores e, dessa forma, o apelo às recordações pressupõe aquilo que ele deveria explicar. E, no momento em que a evocação das recordações é tornada possível, se torna supérflua, pois o trabalho que dela se espera já está feito. Assim, os estudantes foram levados a refletir sobre o modo de ver as coisas, que nem sempre o que se coloca diante de nós a primeira vista é esgotado por apenas um olhar, é preciso ver o não visto.

Em seguida, foi explanado sobre a Botânica da mandioca, de maneira a considerar o saber local dos agentes sociais para estabelecer um diálogo com os estudantes. Foi explicado que a raiz dessa planta é que dá origem ao seu nome "mandioca", ela apresenta raiz do tipo "tuberosa" porque possui grande concentração de nutrientes acumulados, principalmente carboidratos como o amido. Esta é a parte comestível da planta, no caso da macaxeira, é apenas fervida e, da mandioca que requer um processamento mais complexo para poder servir de alimento, isso muda conforme a variedade da espécie. É a raiz da mandioca que permite a grande quantidade de produtos e subprodutos e se caracteriza como principal fonte de alimentação para a região. 
O gênero Manihot possui cerca de cem espécies. O caule é chamado pelos agentes sociais de "maniva" e, dele que é realizado o processo de cultivo, tão importante para seu modo de existência. No entanto, maniva para eles também pode designar toda a planta como na observação de Seu João: "A maniva é a árvore" (diálogo, julho de 2019).

Aproveitou-se para explicar que a "maniva" possui partes constituintes chamadas nós e entrenós. Cada "nó" corresponde a uma região do caule de onde partem as folhas e a região de segmento entre cada nó adjacente é chamada por sua vez, entrenó. Conforme a planta vai crescendo, isso se torna perceptível e dá uma característica peculiar à maniva (Figura 4). Essa classificação não faz parte do saber dos agricultores que utilizam muito mais a percepção, as sensorialidades para descrever a planta, pois já são difusas a partir do mundo vivido.

Figura 4 - Visualização dos "nós" e "entrenós" no caule da mandioca.

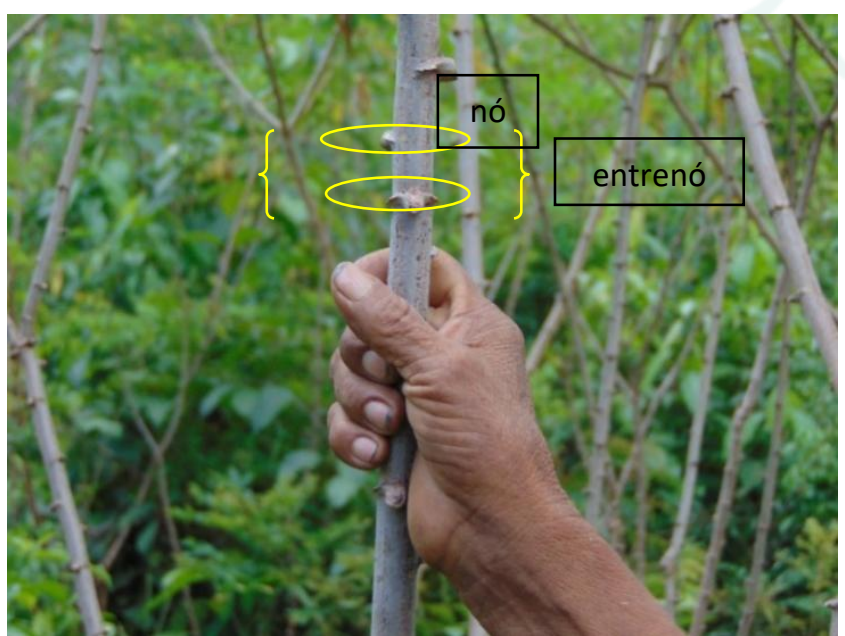

Fonte: Pesquisa de campo, organizado por Batista, 2019.

Eles reconhecem a planta a partir de características morfológicas mesmo que sem noção desse termo botânico. Isso é perceptível quando o agricultor comenta:

Aí no nosso roçado tem várias qualidades, a gente sabe que é diferente na cor da mandioca. Dá pra saber pela planta. A cor da maniva é diferente, aqui tem da verdinha. Lá no vizinho, ele tem duma maniva roxa. Essa que a maniva é roxa, a mandioca é amarelinha. Dessa verdinha que tem aí, é branca a maniva dela (Seu JOÃO, diálogo, maio de 2019). 
Revista do Programa de Pós-Graduação em Educação da Unochapecó

ISSN 1984-1566 (on-line) ISSN 1415-8175 (impressa)

Nesse diálogo, é possível perceber que o agricultor utiliza os termos mandioca e maniva para se referir somente à planta. Quando ele diz que "[...] aqui tem da verdinha. Lá no vizinho, ele tem duma maniva roxa [...]", ele se refere a cor da folha da planta, nesse caso, uma característica morfológica revela o saber sobre a variedade ao qual ele se refere como qualidade.

Este aspecto manifestou um saber a partir da percepção de suas experiências de vida, do contato com a planta, este saber tem sua gênese das experiências empíricas. Os agentes sociais conhecem e nomeiam cada variedade de mandioca de seu roçado. Mas, diferente de uma classificação científica, eles as denominam através de nomenclaturas locais, que atende as necessidades de conhecimentos das espécies de mandioca pelos agrícultores.

Seu João destaca pelo menos três tipos de variedades de mandioca, nomeadas segundo o saber local de: seis mês, mandioca preta (ou pretona) e vinagre. Ele conta que a "seis mês" (seis meses) é assim chamada por conta do tempo que a raiz se desenvolve, a mandioca preta ou pretona se chama assim pela característica da folha escura, o que a difere da vinagre é que esta última é menos escura e suas folhas mais finas.

Em Botânica, as folhas da mandioca são classificadas como simples e possuem um longo pecíolo, a estrutura que fixa a folha ao caule. Ele é chamado pelos agentes sociais de "talo" e, dependendo da variedade, possuem diferente coloração. Baseado na percepção do mundo vivido, seu João consegue identificar as variedades a partir dessa coloração e inclusive, consegue descrever a cor da raiz, a partir disso, ele comenta "a de talo verde é amarela, da roxa é branca” (Seu JOÃO, diálogo, jul. de 2019). Esses “detalhes” que para nós não são difusos, não nos permite, ou nos limita a reconhecer a planta a partir dessas características morfológicas. Todas essas questões foram discutidas com os estudantes.

No terceiro momento da oficina, novamente no laboratório de Ciências, os estudantes realizaram a leitura de dois textos informativos referentes ao conhecimento sobre a mandioca, seguido de discussões e socialização dos entendimentos. O primeiro texto era um fragmento do livro 'Plantas da ilha de Duraka’, com informações acerca da

\footnotetext{
7 Plantas da ilha de Duraka - São Gabriel da Cachoeira - Amazonas, Estudo etnobotânico. $2^{\mathrm{a}}$ edição/ Madalena Otaviano Aguiar/ Elaine do Nascimento Malheiros Freitas. Manaus. Editora Valer. PPBio-Inpa, 2006. Ver páginas 45 a 47.
} 
Revista do Programa de Pós-Graduação em Educação da Unochapecó

ISSN 1984-1566 (on-line) ISSN 1415-8175 (impressa)

mandioca e o segundo texto uma nota científica ${ }^{8}$. Os estudantes falaram que foi possível perceber a questão dos produtos originados da mandioca, que estes fazem parte de seu dia a dia, mas que não prestavam atenção o quanto havia proximidade com eles.

Perguntaram então sobre a diferença entre a mandioca e a macaxeira. Foi destacado que a mandioca se difere da macaxeira devido ao alto teor de uma substância presente na raiz. Eles socializaram alguns saberes como "se comer a mandioca dá dor de estômago", "no filme que nós assistimos, o menino comeu a mandioca e morreu", "não pode comer a mandioca senão morre”. Questionados quanto a isso eles responderam que "tem que cozinhar a macaxeira”, “a mandioca tem que ralar", “tem que torrar" (ESTUDANTES, out. de 2019) referindo-se às etapas para retirada do alto teor de toxicidade e produçao de subproduto.

Explicou-se que é no floema (tecido condutor presente na planta e responsável pela distribuição de seiva elaborada, constituída, por exemplo, de aminoácidos e açúcares) que se apresenta uma substância, a linamarina (glicosídeo cianogênico) que, ao sofrer um processo químico (hidrólise) libera o ácido cianídrico (HCN), que é a substância venenosa desta planta, por isso é classificada como uma espécie cianogênica. Ao entrar em contato com as enzimas e ácidos dos sucos digestivos causam intoxicação a partir da liberação do ácido cianídrico. Esse ácido, se ingerido sem nenhum processamento, causa envenenamento tanto em seres humanos quanto em outros animais, por isso, faz-se necessário um procedimento para eliminação dessa substância. A agricultora Dona Maria diz a esse respeito:

A mandioca ela tem veneno, mata mesmo, Deus o livre!, se não fizer todo esse processo direitinho a gente passa mal, até morre. Um dia o gado entrou pra lá pro roçado de noite, comeram tudinho o roçado, quando foi cedo já tinha um monte morto, bem feito quem manda entrar pra lá [risos], mas Deus o livre, é horrível (Dona MARIA, diálogo, jul. de 2019).

Com algumas raízes de mandioca sobre a bancada, percebeu-se que nenhum dos estudantes teve curiosidade de tocá-la e, quando perguntados, um deles brincou "não vou

\footnotetext{
${ }^{8}$ A nota referente é intitulada Mandioca e macaxeira (Manihot Mill.) como tema transversal na escola rural do ensino fundamental no Amazonas, Brasil. Vieira et al, 2007. Ver http://www.ufrgs.br/seerbio/ojs/index.php/rbb/article/view/51 Acesso em 12 set. 2019.
} 
pegar não professor por que tem veneno, vai que eu pego e..." provocando risos entre eles. Esse foi o momento em que puderam se aproximar e tocá-la, descascar para ver por dentro, sentir o cheiro, a textura.

Posteriormente, no espaço "casa de farinha" (Figura 6), os estudantes foram perguntados sobre quem já conhecia ou tinha contato direto com o procedimento de preparo de farinha. Apenas três alunos responderam que sim. Um deles comentou “Eu já vi, minha avó mora no interior, ela faz. Eu já fiz até a parte de descascar, o resto eu fico olhando, não sei como é, eu nunca parei pra aprender". Outro estudante disse "Também, os meus avós, que moram no interior, eu sei que leva a mandioca pra descascar, acho que é isso, mas eu não tenho muito contato não" (ESTUDANTES, out. de 2019).

Figura 6 - Exploração do espaço pelos estudantes participantes da pesquisa para explicar o processo de produção da farinha.

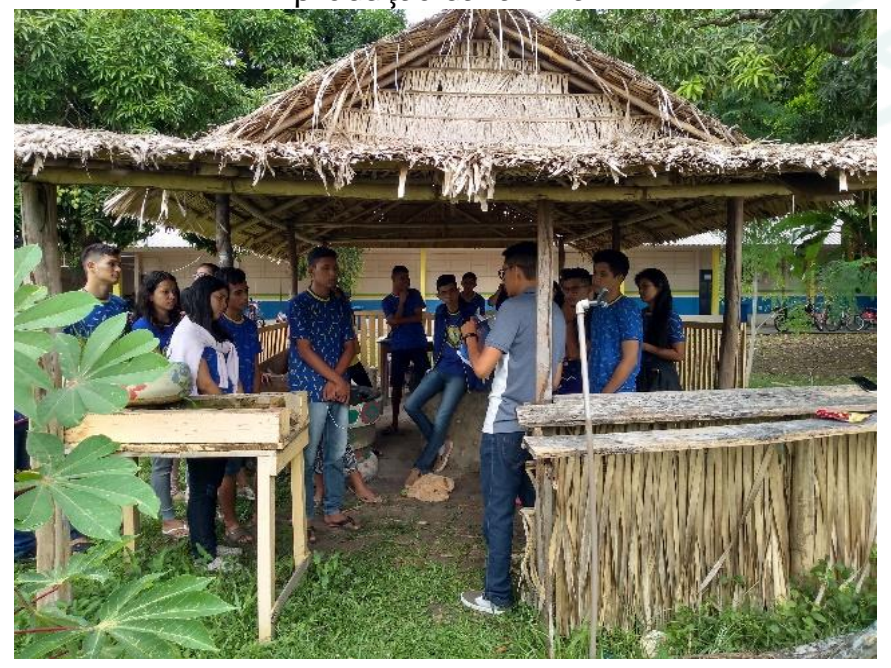

Fonte: Pesquisa de campo, 2019.

Percebeu-se que grande parte dos estudantes não tem contato direto com a agricultura, desconhecendo o processo, alguém até brincou dizendo “o mais importante é comer a farinha, professor!"”. Comentou-se com eles sobre o trabalho do agricultor, todo trabalho é árduo, requer esforço e dedicação, no caso dos agricultores, o objetivo final é produzir uma farinha de qualidade, mesmo com as intempéries eles fazem com dedicação

\footnotetext{
9 É importante frisar que nenhum outro procedimento como, por exemplo, entrevista ou conversa individual, o contato familiar com os estudantes para conhecer seu dia a dia foram adotados nesta pesquisa, o que impede de afirmar que algum estudante deixou de falar a respeito e informar que sejam filhos ou netos de agricultores.
} 
Revista do Programa de Pós-Graduação em Educação da Unochapecó

ISSN 1984-1566 (on-line) ISSN 1415-8175 (impressa)

e prazer, isso dignifica seu trabalho. Por fim, comentou-se que a casa de farinha constitui um espaço essencial ao trabalho dos agentes sociais na preparação de seus produtos.

Os estudantes realizaram questionamentos e tiraram dúvidas sobre o procedimento. Disseram que não sabiam sobre a maneira de produzir farinha, demonstrando curiosidade. Perguntados sobre o que eles haviam relacionado sobre o saber local do cultivo com a Botânica: "Está relacionado de várias maneiras, desde os conhecimentos culinários aplicados na alimentação diária, como os saberes locais passados de geração em geração", comentou um dos estudantes.

Eles relataram os produtos dessa planta (mandioca) estão na alimentação do dia a dia, seja por meio do beiju, da tapioca, da farinha, do fritinho de cruera, da macaxeira cozida, enfim, que as plantas realmente têm uma relação muito aproximada com a vida do ser humano desde tempos históricos.

\section{CONSIDERAÇÕES FINAIS}

Este trabalho visou compreender as possíveis articulações dos saberes locais de agricultores sobre a mandioca com o ensino de Botânica na Biologia. Entende-se que é preciso mudar a forma de "ver" para perceber o mundo do outro, pois a tentativa de observar a realidade do outro a partir da centralidade da nossa concepção age como uma forma de exclusão e compreensão dos modos diferentes de ser, de pensar e de viver do outro.

As atividades desenvolvidas se constituíram em um momento de enriquecimento e um diálogo entre os saberes, criando a possibilidade para que os estudantes refletissem sobre a relação do ser humano com a natureza, que diante de um mundo se constrói saberes com base nas vivências e na percepção que se tem a partir dele. A intenção não era que os estudantes aprendessem tudo quanto possível sobre a Botânica da mandioca, mas que percebessem que diferentes saberes precisam coexistir, utilizar em nossa vida o que aprendemos na vivência e os aprimoramentos obtidos na mediação pelo saber escolarizado.

Considera-se, por fim, que a valorização dos saberes locais para o Ensino de Ciências se faz necessária para não se cair num objetivismo extremo, mas dar vez e voz aos saberes 
Revista do Programa de Pós-Graduação em Educação da Unochapecó

ISSN 1984-1566 (on-line) ISSN 1415-8175 (impressa)

tradicionais, no caso deste estudo, dos agricultores que cultivam a mandioca e dominam toda a cadeia produtiva, advindo de diversas comunidades, dos povos que conseguiram criar conhecimentos por meio de suas percepções do mundo experienciado e vivido.

\section{REFERÊNCIAS}

AGUIAR, Madalena Otaviano; FREITAS, Elaine do Nascimento Malheiros (orgs). Plantas da Ilha de Duraka - São Gabriel da Cachoeira - Amazonas: estudo etnobotânico. 2. ed., Editora Valer, PPBio-INPA, Manaus, 2006.

BECKER, Howard Saul. Métodos de pesquisa em Ciências sociais. Hucitec Editora, São Paulo, 1993.

BICUDO, Maria Aparecida Viggiani. Sobre a Fenomenologia. In: BICUDO, Maria Aparecida Viggiani; EXPOSITO, Vitória Helena (orgs.). A pesquisa qualitativa em educação: um enfoque fenomenológico. Piracicaba: Editora Unimep, 1994.

BOURDIEU, Pierre. A miséria do mundo. Petrópolis: Vozes, 4. ed., 2001.

BRASIL. Ministério da Educação. Base Nacional Comum Curricular. Educação é a base. Versão final, Brasília, MEC/CONSED/UNDIME, 2017. Disponível em: http://basenacionalcomum.mec.gov.br. Acesso em: 18 nov. 2018.

DUTRA, Ana Paula; GÜLLICH, Roque Ismael da Costa. A Botânica e suas metodologias de ensino. Revista da SBEnBIO - Associação brasileira de ensino de biologia, n 7, 2014.

FINI, Maria Inês. Sobre a pesquisa qualitativa em Educação, que tem a Fenomenologia como suporte. In: Maria Aparecida Viggiani Bicudo e Vitória Helena Exposito (orgs.). A pesquisa qualitativa em educação: um enfoque fenomenológico. Piracicaba: Editora Unimep, 1994.

FOUCAULT, Michel. A arqueologia do saber. Tradução de Luiz Felipe Baeta Neves, 7. ed., Rio de Janeiro: Forense Universitária, 2008.

GEERTZ, Clifford. O saber local: novos ensaios em antropologia interpretativa. 14. ed., 2. reimpressão (Trad., Joscelyne, V.M.). Coleção antropologia, Petrópolis/RJ: Vozes, 2017.

IPHAN, Instituto do Patrimônio Histórico e Artístico Nacional. Sistema Agrícola Tradicional do Rio Negro. Departamento de Patrimônio imaterial. Dossiê IPHAN: Processo $\mathrm{n}^{\circ}$ 01450.010779/2007-11, 2010.

KUHN, Thomas Samuel. A estrutura das revoluções científicas. São Paulo: Perspectiva, 1998. 
Revista do Programa de Pós-Graduação em Educação da Unochapecó

ISSN 1984-1566 (on-line) ISSN 1415-8175 (impressa)

LEITE, José Carlos; LEITE, Eude Fernandes. Saber formal e Saber local: convergências e assimetrias. Ciências \& Cognição, [S.I.], v. 17, n. 2, set. 2012. ISSN 1806-5821.

LÉVI-STRAUSS, Claude. Mito e significado. Tradução de Antônio Marques Bessa. Perspectivas do homem, Edições 70, 1978.

LÉVI-STRAUSS, Claude. O pensamento selvagem. Tradução Tânia Pellegrini. Campinas, SP, Papirus Editora, 1989, 8. ed., 2008.

LOPES, Alice Ribeiro Casimiro. Bachelard: o filósofo da desilusão. Caderno Brasileiro de Ensino de Física, v.13, n3: p.248-273, dez. 1996.

MARTINS, Joel; BICUDO, Maria Aparecida Viggiani. Estudos sobre existencialismo, fenomenologia e educação. São Paulo: Moraes, 1983.

MERLEAU-PONTY, Maurice. Fenomenologia da percepção. Tradução Carlos Alberto Ribeiro de Mota. 5. ed., São Paulo, Editora WMF Martins Fontes, 2018.

SANTOS, Boaventura de Sousa. Um discurso sobre as ciências na transição para uma ciência pós-moderna. Estudos Avançados, São Paulo , v. 2, n. 2, p. 46-71, Aug. 1988. Disponível em:http://www.scielo.br/scielo.php?script=sci_arttext\&pid=S0103-

40141988000200007\&lng=en\&nrm=iso. Acesso em: 28 Mar. 2019. http://dx.doi.org/10.1590/S0103-40141988000200007.

VIEIRA, Maria de Fátima; FRANCISCON, Carlos Henrique; RIBEIRO, Gilberto de Assis; RIBEIRO, Joana Darc; GUSMÃO, Gizelle Amora. Mandioca e macaxeira (Manihot Mill.) como tema transversal na escola rural do ensino fundamental no Amazonas, Brasil. Revista Brasileira de Biociências, Porto Alegre, v. 5, supl. 1, p. 15-17, jul. 2007. Disponível em:http://www.ufrgs.br/seerbio/ojs/index.php/rbb/article/view/51. Acesso em: 24 set 2019.

\section{AGRADECIMENTOS}

À Fundação de Amparo à Pesquisa do Estado do Amazonas - Fapeam, cujo autor na condição de bolsista obteve financiamento para a pesquisa através do Programa de Apoio à Pós-graduação stricto senso POSGRAD.

Enviado em: 21-02-2021

Aceito em: 03-04-2021

Publicado em: 05-04-2021 